\title{
Assessment of Urban Heat Island based on the relationship between Land Surface Temperature and Land Use/Land Cover in Greater Doha
}
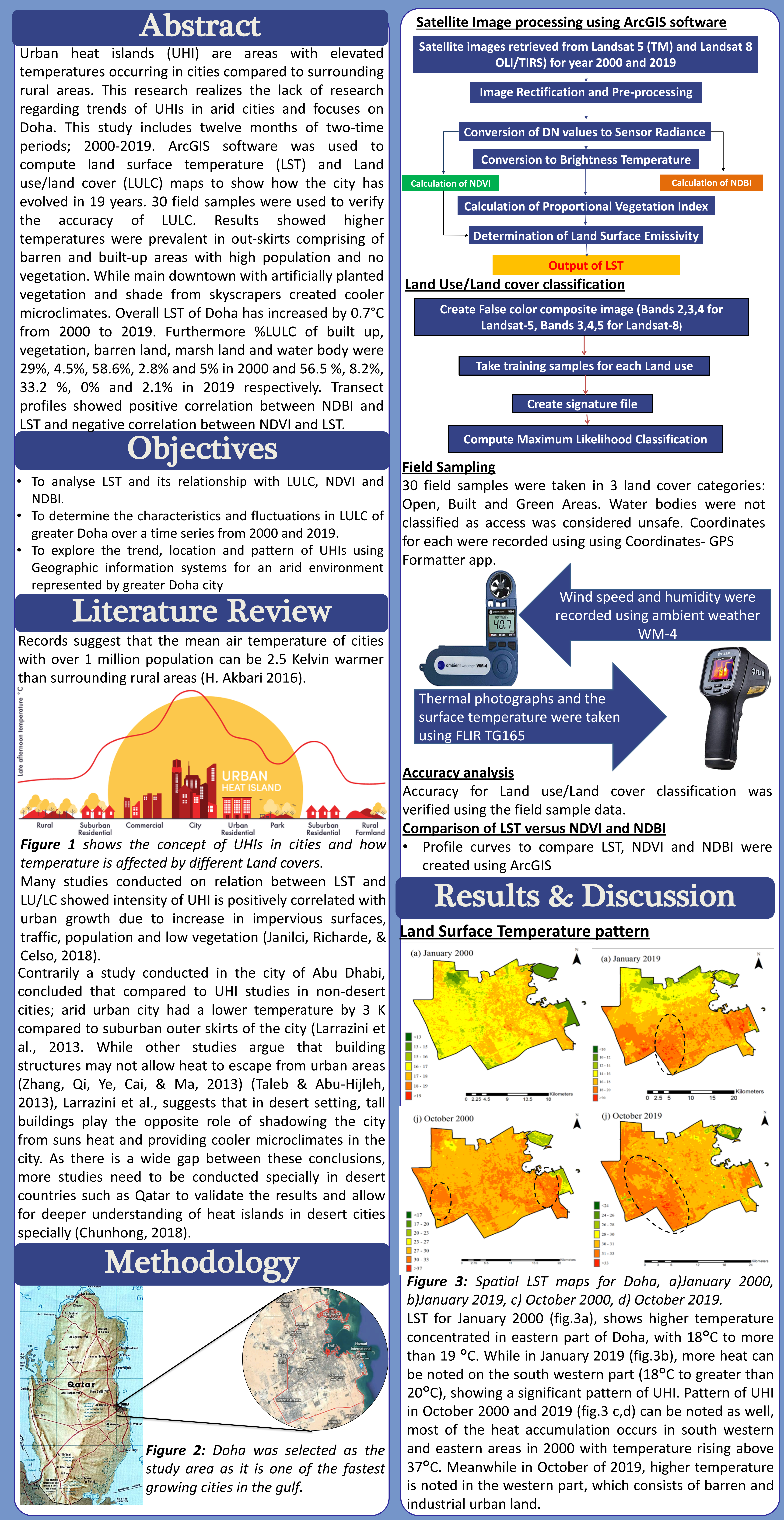

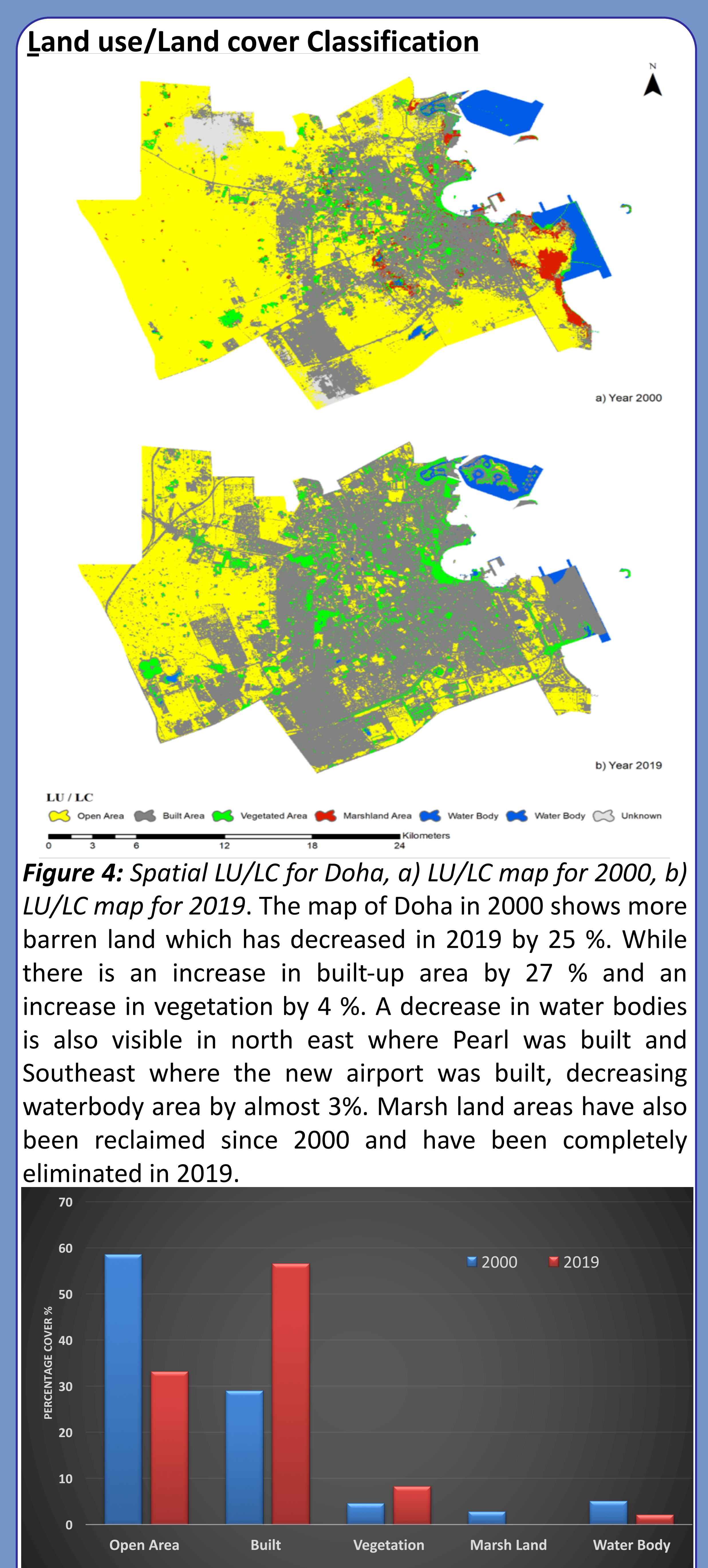

Figure 5: shows the change in land use/land cover from 2000 to 2019. There is an increase in Built up land and vegetation in 2019 and a decrease of Barren area and water body due to reclamation of land for building of areas such as the Pearl and Airport. While Marsh land has

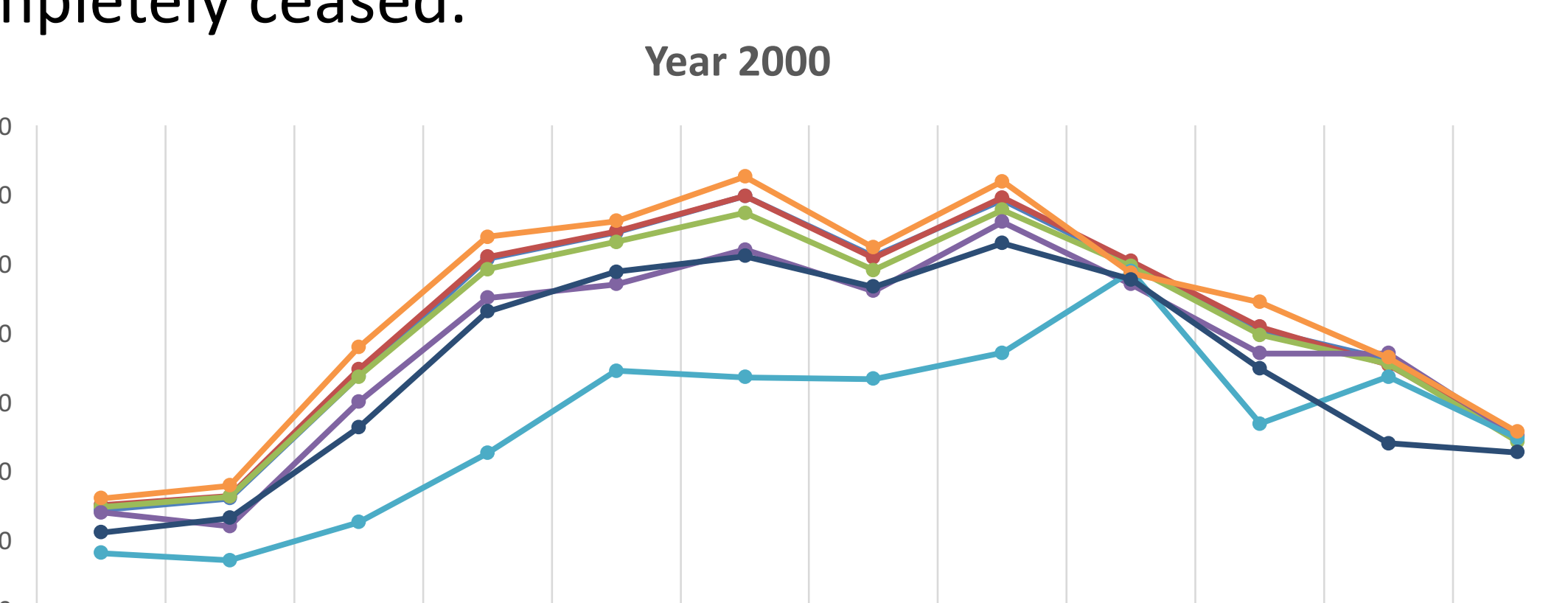

Graph1: Monthly LST for each land use in a)2000, b) 2019. Highest temperatures were found in marsh area class in 2000 and in open and built area classes in 2019. The lowest mean temperatures were recorded for seawater class in both years. In compliance with most UHI studies,
this study shows elevated temperatures in Urban areas. But an unexpected finding of this study was highe

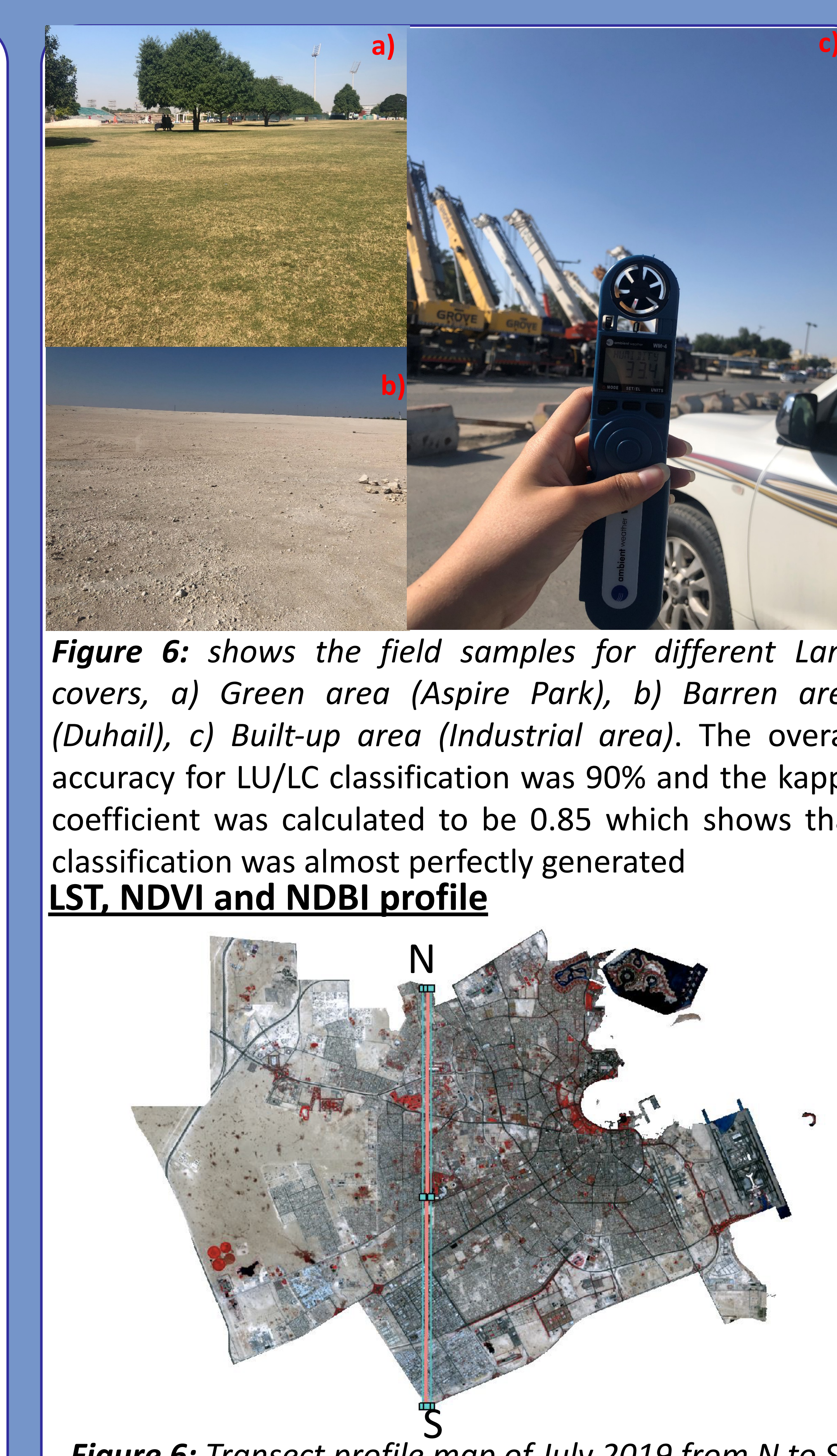

Figure 6: Transect profile map of July 2019 from N to S

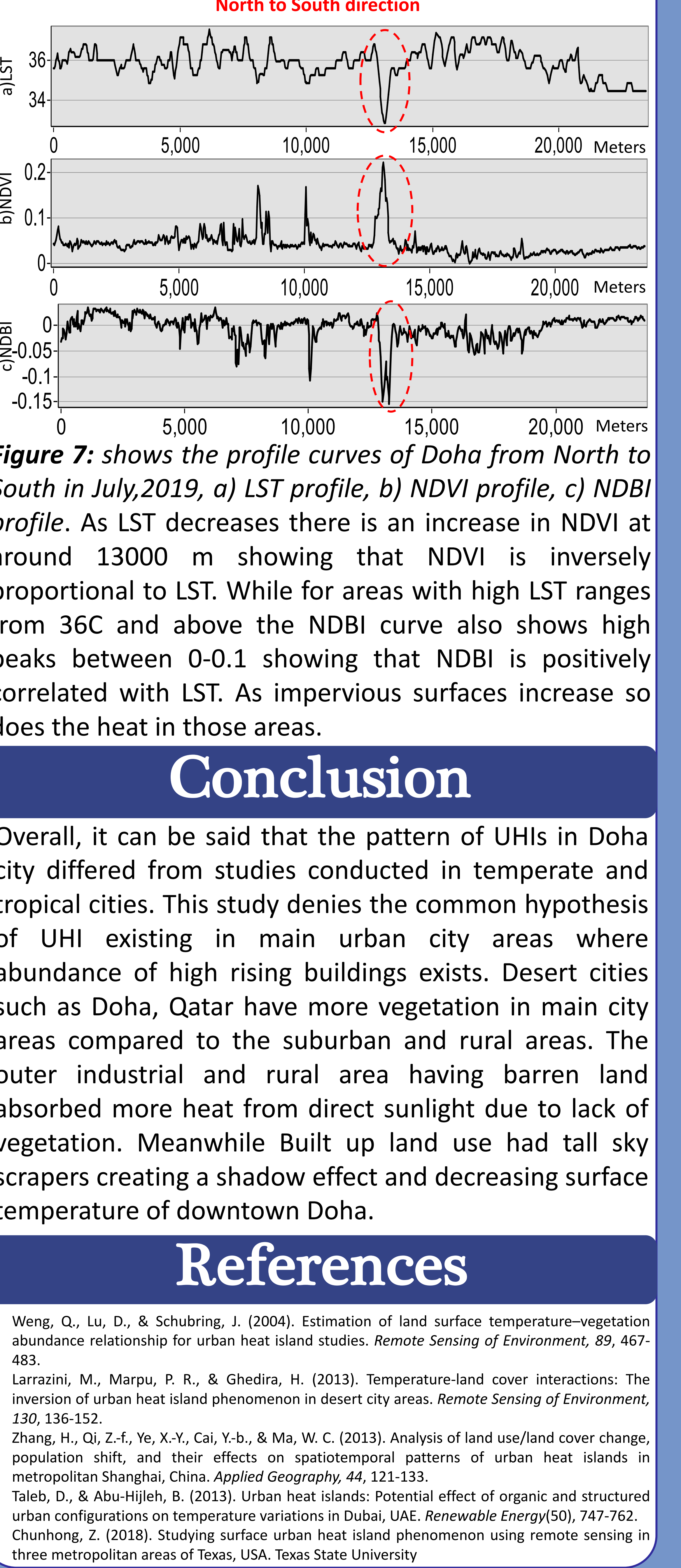

